\title{
I don't have bad Hand-Writing: To Measure the Level of Dysgraphia Among School Children
}

\author{
Hafiza Saba Javaid*, Muneeza Muneer, Maryum Ejaz, Iqra Sattar, Amna \\ Karim and Amna Amjad
}

Department of Clinical Psychology, Government College Women University, Faisalabad, Pakistan

Email of corresponding author: sabasam0307@gmail.com

\begin{abstract}
The purpose of this study was to study to measure the level of dysgraphia among school children. Dysgraphia is actually an inability to write properly within the given margins and space. Many other tests were used in previous research to assess the dysgraphia. Dysgraphia questionnaire was used. It is 22 items scales which is divided into 3 subscales (difficulty in cognition, disorganized motor ability and difficulty in problem solving). Subscale named difficulty in cognition contains 9 items, subscale named disorganized motor ability contains 7 items and subscale named difficulty in problem solving contain 6 items. This study is based on survey method. The sample of $(\mathrm{N}=100)$ students both male and female was selected from Muslims Girls High school and nearby available students of class 6th to 10th and age range from 8 to 16 years by convenient sampling method. There is a significant positive relationship between DIC (Difficulty in Cognition) and DMA (Disorganized Motor Ability) that mean students having disorganized cognitions having disorganized motor abilities as well. There is significant positive relationship between DIC and PS as well that mean problem solving, and cognitions are strongly related to each other and have strong impact. There is a significant positive difference problem solving and age which mean problem solving ability varies with age. There is a significant positive difference between DMA and age as well. There exists a significant difference between PS and family system. A significant difference exits between PS and class of the participant.
\end{abstract}

Keywords: Dysgraphia; Difficulty in Cognition; Disorganized Motor Ability; Difficulty in Problem Solving.

\section{INTRODUCTION}

Dysgraphia is a brain related problem, actually it is a deficiency in the ability to write, primarily handwriting that affects the fine muscles resultantly causes the immobility of fine muscles like finger muscles. Dysgraphia can be differentiated from dyslexia as dyslexia is characterized by ambiguous, disorganized, and irregular handwritings with inconsistent spacing between letter/alphabets, upper and lower case at wrong places, different shapes of alphabets and different unusual style of writing (Hen-Herbst, L., \& Rosenblum, S. 2019).

Dysgraphia is an issue related to our nervous system characterized by affected coordination between small muscles, which we call fine motor skills. These skills are required to write. Disturbed fine motor skills affect the written assignment and tasks. Wellbeing facilitators and utmost clinicians term this disorder "written issue and expression disability" (Crouch, A. L., \& Jakubecy, J. J. 2007). Dysgraphia should not be misunderstood with dyslexia as dyslexia include struggling with reading and it can also affect writing, spellings and speaking. When a child cannot read properly how can he write effectively. But in case of dysgraphia child can read properly but has slow \& labored writing (Safran, J. S. 2002).

Explaining the origin of dysgraphia according to University of Delaware's Online Asperger Syndrome Information and Support has been unclear, depending on how you look at it. There are two subtypes: specific and nonspecific dysgraphia. The specific form of the disease refers more to neurological problems that impact motor skills. Nonspecific dysgraphia points to external impacts as the root cause, such as psychosocial problems or absenteeism in school (Samodro, P. W., \& Sihwi, S. W. 2019).

To classify dysgraphia in international conference on children the implementation of the back propagation. This study produced Accuracy of $94.71 \%$, while conducted research on the characteristics that can be used for writing skills in dysgraphia children. The Identification and rating of developmental dysgraphia by handwriting analysis, the developmental dysgraphia is a disturbance or difficulty in the production of written language that has to do with the mechanics of writing (Rosenblum, S. 2016). 
European conduct the analysis of Parkinson's disease on dysgraphia based optimized fractional order derivative features. According to that study the majority of Parkinson's disease patients is associated with handwriting abnormalities called Parkinson's disease dysgraphia, which is linked with rigidity and bradykinesia of muscles involved in the handwriting process (Lopez-de-Ipina, K. 2019).

According to the Biomedical and Health Informatics, addressing dysgraphia with a mobile, web-based software with interactive feedback. Dysgraphia has a non-indifferent role since it undermines the writing communication abilities of the students, with side effects on their self-esteem and a great risk of overcome school performance and more difficult relationships with classmates (Giordano, D., \& Maiorana, F. 2014).

According to research, the generality of Dysgraphia is more in males rather than in females and typically is diagnosed at the 2 or 3 level when writing is more meaningful. Treatment varies for dysgraphia and could consist of the treatment for fine motor skills and how to write effectively. Other treatments could label diminished memory or other nervous problems (Tankard Carnock, J., \& Silva, E. 2019). Roughly physicians propose that people with dysgraphia use computer to avoid handwriting. Some individuals refine their writing ability with dysgraphia, but for others, the disorder continue (Molinari, M. 1997).

\section{LITERATURE REVIEW}

According to research, the prevalence of Dysgraphia is higher in boys than in girls and typically is diagnosed at the 2 nd or 3rd grade level when writing is more substantial (Leach,M. 2009) ("History - The Chronicles of Dysgraphia", 2019). nervous system issue that controls the delicate motor skills want to write. Mark as solid for a child to do handwriting tasks and tasks. Health facilitators and most doctors define this condition "in written form, expression and incapacity"(Cold et al., 2019)

Studies appeared spelling and dysgraphia classified in operational memory is related to handwriting and is often a problem in dysgraphia. The spelling classification discusses the skill to store written words in the working memory while spelling the word expression or the ability to create continuous memory of written words associated with their meaning, articulation and word are examined. Children do not have a primary growing motor disorder, another problem of poor handwriting look, but they may have difficulty planning consecutive finger movements with dysgraphia such as the impression of the thumb on following fingers on the same hand without a visible reaction. Children may have difficulty with spelling organization and preparation for consecutive finger movements with dysgraphia ("Understanding handwriting", 2019).

Harm in even one aspect of the creative writing cycle can weaken a person's capacity to produce an age-fitting item. Despite the fact that analysts have estimated that diverse subtypes of dysgraphia might be connected to various components, fresher investigations have exhibited interrelations between cerebrum regions liable for automaticity, language, and engine coordination. The apparent difference between hypotheses of dysgraphia may not be pretty much as extraordinary as when suspected. For instance, youngsters with dyslexia have additionally been noted to be at expanded danger for other gentle engine shortages in errands like finger tapping, riding a bicycle, and tying shoelaces (Chung, Patel and Nizami, 2020).

Large numbers of the speculations in regards to components of dysgraphia have been gotten from investigations of people with gained dysgraphia. Composing has been demonstrated to be a perplexing cycle that requires the higher request insight (language, verbal working memory and association) facilitated with engine arranging and execution to comprise the practical composing framework (Chung, Patel and Nizami, 2020).

Despite education exposure, $5 \%$ to $10 \%$ of children never reach a sufficient level of automation in handwriting. These handwriting difficulties, termed dysgraphia, affect legibility and/or speed and can seriously impact both children's behavioral and academical development (Gargot et al., 2020).

\section{RATIONALE}

The rationale of the study is to uncover the association between domains of dysgraphia as many children has difficulty in cognition of 
different things if this is corrected dysgraphia can be corrected. Similarly problem solving ability is also affected by difficulty in cognition. So problem solving skills are improved by improving the cognition only if we know how they are related to each other.

\section{OBJECTIVE}

The objective of the study to measure the level of dysgraphia among school children.

\section{HYPOTHESIS}

It is hypothesized that there is significant relationship between Difficulty in cognition and disorganized motor ability

It is hypothesized that there is significant relationship between difficulty in cognition and Difficulty in problem solving.

It is hypothesized that there is significant relationship between disorganised motor ability and difficulty in problem solving.

It is hypothesized that there is significant difference between demographic variables and domains of Dysgraphia Questionnaire.

\section{METHODOLOGY}

The population of the study was school level children. The sample selected for the study was students of class 4 th to 10 th. We selected 100 students from different school both private and government. We selected the sample by convenient sampling technique.

Dysgraphia questionnaire developed by Yaqoob, N., Ejaz, M \& Sattar, I (2019) was used in this study. It is in 5-point likert format ranging from strongly disagree to strongly agree. It has 22 items, divided into 3 domains. First domain named "Difficulty in Cognition" has nine items. Second domain named "Disorganized Motor Ability" has 7 items. Third domain named "Problem Solving" has 6 items. This questionnaire was selected because of measurement of these three domains of dysgraphia.

This study is based on survey method. The independent variables were mentioned that age, gender, socioeconomic status, family system, class and institute. Dependent variables were dysgraphia and its domains (cognition, motor ability and problem solving). The extraneous variable was the teaching method. There was no control variable in the study.

A bundle containing inform consent, demographic sheet and dysgraphia questionnaire was given to subjects. Firstly, the purpose of the study was elaborated to the subjects. Then, their consent was taken. The subjects were instructed as; according to guidance using the scale, it indicates how much you agree or disagree by placing the $\mathrm{X}$ in appropriate place with the following statement. Subjects completed the questionnaire according to their level of difficulty they face in writing. The results were calculated according to the scoring of the questionnaire. All the data and demographic variables were entered to SPSS for statistical analysis.

\section{RESULTS}

Table 1 indicates the frequencies and percentage of demographic variable of the participants. The table indicates that $29 \%$ of the participants are of age 8-12 and $71 \%$ are from age 13-16. There are $53 \%$ boys and $47 \%$ girls.52\% of the participants are from govt. sectors and rest $48 \%$ are from private sector schools. $27 \%$ participants having trouble to write English while 39\% have trouble in Urdu and $34 \%$ population having trouble in writing both languages.

The Dysgraphia Questionnaire having three domains. The first one DIC consists of 9 items in it and having reliability. 691.The second domain DMA consists of 7 items in it having reliability .335. Third domains have 6 items in it and have .467 Cronbach's alpha value.

There is a significant positive relationship between DIC and DMA that mean students having disorganized cognitions having disorganized motor abilities as well. There is significant positive relationship between DIC and PS as well that mean problem solving, and cognitions are strongly related to each other and have strong impact.

There is a significant positive difference problem solving and age which mean problem solving ability varies with age. There is a significant positive difference between DMA and age as well. There exists a significant difference between PS and family system. A significant difference exits between PS and class of the participant. 
Table 1: Demographic Variables of the Study $(\mathrm{N}=100)$

\begin{tabular}{|llll|}
\hline Variables & & f & \% \\
Age & $08-12$ & 29 & 29.0 \\
Gender & $13-16$ & 71 & 71.0 \\
SES & Boy & 53 & 53.0 \\
& Girl & 47 & 47.0 \\
& Low & 7 & 7.0 \\
Family & Middle & 87 & 87.0 \\
\multirow{3}{*}{ Class of Participant } & High & 6 & 6.0 \\
\multirow{3}{*}{ Residence } & Nuclear & 53 & 53.0 \\
& High & 47 & 47.0 \\
Writing Problem of the Participant & Four to seven & 42 & 42.0 \\
& Eight to ten & 58 & 58.0 \\
Institute of the Participant & Village & 29 & 29.0 \\
& City & 71 & 71.0 \\
& Urdu & 27 & 27.0 \\
& Both & 39 & 39.0 \\
& Govt. & 34 & 34.0 \\
& Private & 52 & 52.0 \\
\hline
\end{tabular}

Table 2: Mean and Standard Deviations of Demographic Variable of the Participants

\begin{tabular}{|llll|}
\hline Variables & N & M & SD \\
Age & 100 & 1.71 & .456 \\
Gender & 100 & 1.47 & .502 \\
SES & 100 & 1.99 & .362 \\
Family & 100 & 1.47 & .502 \\
Class of Participant & 100 & 1.58 & .496 \\
Residence & 100 & 1.71 & .456 \\
Writing Problem of the Participant & 100 & 2.07 & .782 \\
Institute of the Participant & 100 & 1.48 & .502 \\
\hline
\end{tabular}

Key: SES=socio economic status

Table 3: Reliability Index, Item Details, Number of Items, Mean and Cronbach's Alpha of Dysgraphia Questionnaire (DQ)

\begin{tabular}{|llcllll|}
\hline Scale & Item Numbers in scales & Numbers & of Items & Mean & SD & Cronbach's Alpha \\
DQ & $1-22$ & 22 & 64.59 & 10.670 & .710 \\
\hline
\end{tabular}

Key: $\mathrm{DQ}=$ dysgraphia questionnaire

Table 4: Correlations Between Three Domains of the Scale

\begin{tabular}{llll|}
\hline Variables & DIC & DMA & PS \\
DIC & 1 & $.324^{* *}$ & $.373^{* *}$ \\
DMA & & 1 & .176 \\
PS & & 1 \\
\hline Key: **P<0.01, DIC=difficulty in cognition, DMA=disorganized motor ability, PS=problem solving
\end{tabular}


Table 5: Independent Sample T Test of DQ and Demographic Variables

\begin{tabular}{|c|c|c|c|c|c|c|c|}
\hline \multirow{3}{*}{$\begin{array}{l}\text { Variables } \\
\text { DIC }\end{array}$} & & \multirow{3}{*}{$\begin{array}{l}\mathbf{N} \\
29 \\
71\end{array}$} & \multirow{3}{*}{$\begin{array}{l}\text { Mean } \\
25.1379 \\
25.8873\end{array}$} & \multirow{2}{*}{$\begin{array}{l}\text { SD } \\
6.1454\end{array}$} & \multirow{3}{*}{$\begin{array}{l}\mathbf{t} \\
-.528\end{array}$} & \multirow{3}{*}{$\begin{array}{l}\mathbf{P} \\
.599\end{array}$} & \multirow{3}{*}{$\begin{array}{l}\text { Cohen's d } \\
0.117\end{array}$} \\
\hline & $8-12$ & & & & & & \\
\hline & $13-16$ & & & 6.5542 & & & \\
\hline \multirow[t]{2}{*}{ DMA } & $8-12$ & 29 & 22.8966 & 2.8074 & \multirow{2}{*}{2.064} & \multirow{2}{*}{.042} & \multirow{2}{*}{0.484} \\
\hline & $13-16$ & 71 & 21.2535 & 3.8866 & & & \\
\hline \multirow[t]{2}{*}{ PS } & $8-12$ & 29 & 19.7241 & 4.2501 & \multirow{2}{*}{2.437} & \multirow{2}{*}{.017} & \multirow{2}{*}{0.523} \\
\hline & $13-16$ & 71 & 17.6197 & 3.7772 & & & \\
\hline \multirow[t]{2}{*}{ DIC } & Boy & 53 & 25.8679 & 6.0638 & \multirow{2}{*}{.326} & \multirow{2}{*}{.745} & \multirow{2}{*}{0.065} \\
\hline & Girl & 47 & 25.4468 & 6.8518 & & & \\
\hline \multirow[t]{2}{*}{ DMA } & Boy & 53 & 21.6604 & 3.5352 & \multirow{2}{*}{-.200} & \multirow{2}{*}{.842} & \multirow{2}{*}{0.040} \\
\hline & Girl & 47 & 21.8085 & 3.8540 & & & \\
\hline \multirow[t]{2}{*}{ PS } & Boy & 53 & 17.9623 & 3.7001 & \multirow{2}{*}{-.706} & \multirow{2}{*}{.842} & \multirow{2}{*}{0.140} \\
\hline & Girl & 47 & 18.5319 & 4.3631 & & & \\
\hline DIC & Nuclear & 53 & 26.0337 & 6.4359 & 607 & 515 & O 12 \\
\hline & Joint & 47 & 25.2553 & 6.4385 & (. & $.04 J$ & 0.120 \\
\hline DMA & Nuclear & 53 & 22.0000 & 3.3569 & 780 & 437 & 0156 \\
\hline & Joint & 47 & 21.4225 & 4.0094 & .100 & I & 0.150 \\
\hline PS & Nuclear & 53 & 18.8811 & 3.9975 & 2017 & 046 & 0379 \\
\hline & Joint & 47 & 17.3830 & 3.9040 & 2.017 & טד. & נוס.0 \\
\hline DIC & Class 4-7 & 42 & 26.1667 & 6.7060 & 657 & 513 & 0132 \\
\hline & Class8-10 & 58 & 25.3103 & 6.2329 & ו ונט. & נדונ. & 0.152 \\
\hline DMA & Class 4-7 & 42 & 22.9048 & 2.8094 & 2817 & 006 & 0586 \\
\hline & Class8-10 & 58 & 20.8793 & 3.9959 & 2.017 & .000 & 0.000 \\
\hline PS & Class 4-7 & 42 & 19.4048 & 3.7158 & 2550 & 012 & 0523 \\
\hline & Class8-10 & 58 & 17.3739 & 4.0385 & 2.00 & .012 & 0.025 \\
\hline DIC & village & 29 & 24.5517 & 5.0609 & 1115 & 267 & 0260 \\
\hline & City & 71 & 26.1268 & 6.8742 & (1.11 & 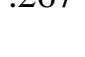 & 0.200 \\
\hline DMA & Village & 29 & 20.9655 & 4.4839 & -1336 & 185 & 0274 \\
\hline & City & 71 & 22.0423 & 3.2664 & & & \\
\hline PS & Village & 29 & 17.9310 & 3.0929 & -474 & 637 & 0.112 \\
\hline & City & 71 & 18.3521 & 4.3493 & & & \\
\hline DIC & Govt. & 52 & 25.8462 & 6.7078 & 284 & 777 & 0057 \\
\hline & Private & 48 & 25.4792 & 6.1505 & .204 & ו & ו \\
\hline DMA & Govt. & 52 & 22.0962 & 3.4937 & 1020 & 201 & 0207 \\
\hline & Private & 48 & 21.3333 & 3.8500 & 1.059 & .001 & 0.207 \\
\hline PS & Govt. & 52 & 17.8269 & 4.0811 & 1045 & 200 & 0216 \\
\hline & Private & 48 & 18.6667 & 3.9937 & $-1.04 J$ & .290 & 0.210 \\
\hline
\end{tabular}

Key: **P $<0.01,{ }^{*} \mathrm{p}<0.05$, DIC=difficulty in cognition, DMA=disorganized motor ability, PS=problem solving 


\section{DISCUSSION}

To ensure the level of dysgraphia among the school children, Dysgraphia scale which has three domains as Difficulty in cognition, disorganized motor ability and problem solving is used to assess its level. Mean value of this scale is (64.59) and SD is (10.670). There is a significant positive relationship between DIC and DMA that mean students having disorganized cognitions having disorganized motor abilities as well. There is significant positive relationship between DIC and PS as well that mean problem solving, and cognitions are strongly related to each other and have strong impact.

A previous research was mentioned below to be conducted to find the comparison between handwriting performance and organizational abilities among children with and without dysgraphia. The result showed that significant correlation was found in dysgraphia group between Handwriting spatial planning and the organizational ability. At also showed that significant differences were found in between handwriting spatial arrangement and the organizational ability (Elsevier 2009).

Another research was mentioned to be conducted on Handwriting development in level 2 and level 3 primary school children with normal, abnormal, or dysgraphia characteristics. In this longitudinal and cross-sectional study, children in grade 2 (age $7-8$ years) and grade 3 (8-9 years) took handwriting and disorganized motor ability and also problem solving tests within one school year.

Dysgraphia decreased strongly from $37 \%$ to $17 \%$ in grade 2 and reduced further to a low and stable rate of $6 \%$ in grade 3. Stability in handwriting quality only happened in the children whose scores were within the normal range and dysgraphic children sustained to show significant and substantial improvement during grades 2 and 3. (Elsevier 2010)

A study was conducted to find the relationship between perceptual motor skill and handwriting in dysgraphia ham-fisted and normal children. The finding of the study reveals a significant correlation among handwriting and perceptual motor skills. (MAELAND 1992)

\section{CONCLUSION}

There is a significant positive relationship between DIC and DMA that mean students having disorganized cognitions having disorganized motor abilities as well. There is significant positive relationship between DIC and PS as well that mean problem solving, and cognitions are strongly related to each other and have strong impact.

There is a significant positive difference problem solving and age which mean problem solving ability varies with age. There is a significant positive difference between DMA and age as well. There exists a significant difference between PS and family system. A significant difference exits between PS and class of the participant.

\section{ACKNOWLEDGEMENT}

Authors would like to say thanks to all the people whose contribution play a role in successful execution of this study.

\section{AUTHOR'S CONTRIBUTION}

Conception, design, data collection, literature review and data entry has been done by Muneeza Muneer. Conception, Data collection, scale author, data entry and methodology has been done by Maryum Ejaz. Conception, Data collection, scale author, data entry, analysis and results has been done by Iqra Sattar. Conception, Data collection, data entry, discussion and conclusion has been done by Amna Karim and Amna Amjad. Drafting the article or revising it critically for important intellectual content; and final approval of the version to be published has been done by Hafiza Saba Javaid.

DISCLOSURES ABOUT POTENTIAL CONFLICT OF INTERESTS

None

FURTHER INFORMATION (E.G., FUNDING, CONFERENCE PRESENTATION

None 


\section{REFERENCES}

[1] Chung, P., Patel, D., \& Nizami, I. (2020). Disorder of written expression and dysgraphia: definition, diagnosis, and management. Translational Pediatrics, 9(S1), S46-S54.

[2] Cold, F., Health, E., Disease, H., Disease, L., Management, P., \& Conditions, S. et al. (2019). What Is Dysgraphia? Retrieved from: https://www.webmd.com/add-adhd/childhood-adhd/dysgraphia-facts\#1

[3] Crouch, A. L., \& Jakubecy, J. J. (2007). Dysgraphia: How It Affects a Student's Performance and What Can Be Done about It. TEACHING exceptional children plus, 3(3), n3.

[4] Gargot, T., Asselborn, T., Pellerin, H., Zammouri, I., M. Anzalone, S., \& Casteran, L. et al. (2020). Acquisition of handwriting in children with and without dysgraphia: A computational approach. PLOS ONE, 15(9), e0237575. https://doi.org/10.1371/journal.pone.0237575

[5] Giordano, D., \& Maiorana, F. (2014, June). Addressing dysgraphia with a mobile, web-based software with interactive feedback. In IEEE-EMBS International Conference on Biomedical and Health Informatics (BHI) (pp. 264-268). IEEE. https://doi.org/10.1109/bhi.2014.6864354

[6] Hen-Herbst, L., \& Rosenblum, S. (2019). Which characteristics predict writing capabilities among adolescents with dysgraphia?. Pattern Recognition Letters, 121, 6-12. https://doi.org/10.1016/j.patrec.2018.04.021

[7] History - The Chronicles of Dysgraphia. (2019). Retrieved from: https://sites.google.com/site/describingdysgraphia/history

[8] Maeland, A. F. (1992). Handwriting and perceptual-motor skills in clumsy, dysgraphic, and 'normal'children. Perceptual and motor skills, 75(3_suppl), 1207-1217. https://doi.org/10.2466/pms.75.8.1207-1217

[9] Mekyska, J., Faundez-Zanuy, M., Mzourek, Z., Galaz, Z., Smekal, Z., \& Rosenblum, S. (2016). Identification and rating of developmental dysgraphia by handwriting analysis. IEEE Transactions on Human-Machine Systems, 47(2), 235-248. https://doi.org/10.1109/thms.2016.2586605

[10] Mucha, J., Faundez-Zanuy, M., Mekyska, J., Zvoncak, V., Galaz, Z., Kiska, T., Smekal, Z., Brabenec, L., Rektorova, I., \& Lopez-de-Ipina, K.. (2019). Analysis of Parkinson's Disease Dysgraphia Based on Optimized Fractional Order Derivative Features. 2019 27th European Signal Processing Conference (EUSIPCO) (pp. 1-5). IEEE. https://doi.org/10.23919/eusipco.2019.8903088

[11] Overvelde, A., \& Hulstijn, W. (2011). Handwriting development in grade 2 and grade 3 primary school children with normal, at risk, or dysgraphic characteristics. Research in developmental disabilities, 32(2), 540-548. https://doi.org/10.1016/j.ridd.2010.12.027

[12] Rosenblum, S., Aloni, T., \& Josman, N. (2010). Relationships between handwriting performance and organizational abilities among children with and without dysgraphia: A preliminary study. Research in developmental disabilities, 31(2), 502-509. https://doi.org/10.1016/j.ridd.2009.10.016

[13] Safran, J. S. (2002). A practitioner's guide to resources on Asperger syndrome. Intervention in School and Clinic, 37(5), 283-291. https://doi.org/10.1177/105345120203700504

[14] Samodro, P. W., \& Sihwi, S. W. (2019), March). Backpropagation Implementation To Classify Dysgraphia In Children. 2019 International Conference of Artificial Intelligence and Information Technology (ICAIIT), 437442). IEEE. https://doi.org/10.1109/icaiit.2019.8834520

[15] Silveri, M. C., Misciagna, S., Leggio, M. G., \& Molinari, M. (1997). Spatial dysgraphia and cerebellar lesion: a case report. Neurology, 48(6), 1529-1532. https://doi.org/10.1212/wnl.48.6.1529

[16] Tankard Carnock, J., \& Silva, E. (2019). English Learners with Disabilities: Shining a Light on Dual-Identified Students.

[17] Yaqoob, N., Ejaz, M., Sattar, I.. Development and validation of Dysgraphia Questionnaire. Dept. of Applied Psychology. Govt. College Women University Faisalabad.

Received on 15-08-2021

Accepted on 18-08-2021

Published on 01-09-2021

(C) 2021 Javaid et al.; Licensee ATSK Publishers.

This is an open access article licensed under the terms of the Creative Commons Attribution Non-Commercial License (http://creativecommons.org/licenses/by-nc/3.0/) which permits unrestricted, noncommercial use, distribution and reproduction in any medium, provided the work is properly cited. 


\section{APPENDICES}

\section{Informed Consent Form}

The purpose of this research is to measure the level of Dysgraphia among School children. In this research, your personal information will be asked and you'll be provided a questionnaire to fill. Your participation in this research will be completely voluntary. It is ensured that there is no risk associated with this research. All of yours provided personal information would be kept confidential. You have the right to decline the participation in this research. During data collection, you will have right to ask questions and can withdraw at any point, if you feel uncomfortable.

\section{Researcher's Sign:}

\section{Date:}

I am a student and have agreed to voluntary participate in this research. I verify that the researcher have completely informed me about this research. The researcher has ensured me that there is no risk associated with this research. All of mine personal information will be kept confidential. However, research data could be discussed with supervisor. I will have the right to task questions and can withdraw at any point, if feel uncomfortable.

\section{Participant's Sign:}

\section{Date:}




\begin{tabular}{|c|l|l|l|l|l|}
\hline Difficulty in Cognition & 1 & 2 & $\mathbf{3}$ & $\mathbf{4}$ & $\mathbf{5}$ \\
\hline $\begin{array}{c}\text { Most of the time it feels like I cannot move my } \\
\text { Pencil }\end{array}$ & & & & & \\
\hline I am confused between letters/alphabets & & & & & \\
\hline I feel difficulty in writing alphabets. & & & & & \\
\hline $\begin{array}{l}\text { I often get confused among upper- and lower- } \\
\text { case letters. }\end{array}$ & & & & \\
\hline $\begin{array}{c}\text { Most of the time I feel difficulty in organizing the } \\
\text { words in line }\end{array}$ & & & & & \\
\hline I have a messy handwriting. & & & & & \\
\hline I cannot tap my finger speedily on table. & & & & \\
\hline $\begin{array}{c}\text { I can't connect dots from one point to another to } \\
\text { form a picture }\end{array}$ & & & & & \\
\hline $\begin{array}{c}\text { I forget the spellings of previously learned } \\
\text { vocabulary words while writing. }\end{array}$ & & & & & \\
\hline
\end{tabular}

\section{Dysgraphia Questionnaire}

Instructions: using the scale provided as guide, indicates how much you agree or disagree with the following statement by placing $\mathrm{X}$ in appropriate place. Give only one answer for each statement: (1) strongly disagree, (2) disagree, (3) uncertain, (4) agree, (5) strongly agree

\begin{tabular}{|c|l|l|l|l|l|}
\hline Disorganized motor ability & 1 & 2 & 3 & $\mathbf{4}$ & $\mathbf{5}$ \\
\hline I feel pain in my hand while writing & & & & & \\
\hline $\begin{array}{c}\text { Sometimes I know correct answers in my tests but } \\
\text { I lose marks because I can't write properly. }\end{array}$ & & & & & \\
\hline $\begin{array}{l}\text { I don't have to struggle a lot while expressing my } \\
\text { thoughts into paper }\end{array}$ & & & & \\
\hline Sometimes I have bad grip on pencil. & & & & & \\
\hline $\begin{array}{l}\text { My teacher points out a lot of mistakes on my } \\
\text { notebook }\end{array}$ & & & & \\
\hline Sometimes I omit words in my writing. & & & & & \\
\hline I can complete my written work on time. & & & & & \\
\hline
\end{tabular}




\begin{tabular}{|l|l|l|l|l|l|}
\hline Problem solving & 1 & 2 & 3 & $\mathbf{4}$ & $\mathbf{5}$ \\
\hline I erase a lot while writing. & & & & & \\
\hline I can colour inside the lines. & & & & & \\
\hline $\begin{array}{l}\text { Most of the time I can't retrieve words while } \\
\text { writing. }\end{array}$ & & & & & \\
\hline I cannot write extended response questions & & & & & \\
\hline $\begin{array}{l}\text { Sometimes I am unable to solve arithmetic } \\
\text { Problem. }\end{array}$ & & & & & \\
\hline Most of the time I face spelling problems & & & & & \\
\hline
\end{tabular}

Demographic Form

Age:

Gender:

Socioeconomic status:

Family system:

Class:

Residence:

Writing problem:

Institute:

Name of the Institute:
04-09

Boy

Low

Middle

High

Joint

10-14

Girl

Nuclear
Village

City

Urdu

Both

Private

English

Govt

Private 